\title{
ADC measurements in the evaluation of lymph nodes in patients with non-Hodgkin lymphoma: feasibility study
}

\author{
Thomas C. Kwee - Inge Ludwig - Cuno S. Uiterwaal - Henriette M. E. Quarles van Ufford • \\ Malou A. Vermoolen · Rob Fijnheer • Marc B. Bierings • Rutger A. J. Nievelstein
}

Received: 31 May 2010 / Revised: 18 July 2010 / Accepted: 2 September 2010 / Published online: 24 September 2010

(c) The Author(s) 2010. This article is published with open access at Springerlink.com

\begin{abstract}
Object To determine whether apparent diffusion coefficient (ADC) measurements allow discrimination of normal lymph nodes from lymphomatous lymph nodes, and indolent lymphomas from aggressive lymphomas in patients with nonHodgkin lymphoma (NHL).

Materials and methods Eighteen healthy volunteers and thirty-two patients with newly diagnosed NHL (indolent: $n=16$; aggressive: $n=16$ ) underwent diffusion-weighted imaging. ADCs of normal lymph nodes were compared to those of lymphomatous lymph nodes, and ADCs of indolent lymphomas were compared to those of aggressive lymphomas. Receiver operating characteristic (ROC) analysis was
\end{abstract}

This study was supported by ZonMw Program for Health Care Efficiency Research (grant number 80-82310-98-08012).

T. C. Kwee $(\varangle) \cdot$ H. M. E. Q. van Ufford · M. A. Vermoolen ·

R. A. J. Nievelstein

Department of Radiology, University Medical Center Utrecht,

Heidelberglaan 100, 3584 CX Utrecht, The Netherlands

e-mail: thomaskwee@gmail.com

I. Ludwig

Department of Hematology, University Medical Center Utrecht,

Utrecht, The Netherlands

\section{S. Uiterwaal}

Julius Center for Health Sciences and Primary Care,

University Medical Center Utrecht,

Utrecht, The Netherlands

\section{R. Fijnheer}

Department of Hematology, Meander Medical Center,

Amersfoort, The Netherlands

\section{B. Bierings}

Department of Pediatric Hematology, University Medical

Center Utrecht, Utrecht, The Netherlands performed when ADCs were significantly different between two of the aforementioned groups.

Results ADCs (in $10^{-3} \mathrm{~mm}^{2} / \mathrm{s}$ ) of lymphomatous lymph nodes $(0.70 \pm 0.22)$ were significantly lower $(P<0.0001)$ than those of normal lymph nodes $(1.00 \pm 0.15)$. Area under the ROC curve was 0.865 . Sensitivity and specificity were 78.1 and $100 \%$ when using an optimal cutoff ADC value of 0.80 . On the other hand, ADCs of indolent lymphomas $(0.67 \pm 0.21)$ were not significantly different $(P=0.2997)$ from those of aggressive lymphomas $(0.74 \pm 0.23)$.

Conclusion ADC measurements show promise as a highly specific tool for the discrimination of normal lymph nodes from lymphomatous lymph nodes, but appear to be of no utility in differentiating indolent from aggressive lymphomas.

Keywords Diffusion-weighted magnetic resonance imaging · Apparent diffusion coefficient · Non-Hodgkin lymphoma

\section{Introduction}

Non-Hodgkin lymphomas (NHLs) comprise approximately 4-5\% of all malignancies and are the fourth to fifth most frequently occurring type of cancer in the Western world [1]. In 2009, an estimated 65,980 new cases of NHL will be diagnosed in the United States [1]. Once a NHL has been diagnosed histologically, extent of disease has to be assessed, because this determines prognosis and treatment planning [2,3]. Recently, whole-body diffusion-weighted magnetic resonance (MR) imaging (DWI) was introduced as a new imaging modality for staging malignant lymphoma [4-6]. Both normal and lymphomatous lymph nodes exhibit high signal intensity at DWI [4-6]. Therefore, detection of lymphomatous lymph nodes at DWI still depends on size criteria 
that are regarded as imperfect [7]. On the other hand, DWI allows quantifying diffusion in lymph nodes by means of apparent diffusion coefficient (ADC) measurements, and this may aid in the characterization of lymph nodes. It is expected that malignant tissue, including metastatic lymph nodes, generally exhibits hypercellularity, increased nucleusto-cytoplasm ratios, and an increased amount of macromolecular proteins [8], resulting in a decreased diffusion in the extra- and intracellular compartments (i.e. lower ADC) compared to normal lymph nodes [9]. Previous studies [1015] have shown that ADCs of lymphomatous lymph nodes are generally lower than those of metastatic lymph nodes and benign lymphadenopathy. However, these studies [1015] exclusively investigated pathologic lymph nodes with different histologies and did not compare ADCs of lymphomatous lymph nodes to those of normal lymph nodes. Furthermore, although some studies [16-21] have shown that ADCs of metastatic lymph nodes are significantly different from those of normal lymph nodes, these studies did not include lymphomatous lymph nodes. Moreover, results of different studies are generally not comparable due to the use of different $b$-values, a different number of $b$-values, and different ADC measurement methods. Therefore, it is still unknown whether ADC measurements can be used for discriminating normal lymph nodes from lymphomatous lymph nodes in the staging workup of patients with NHL.

Many subtypes of NHLs exist, but they can grossly be divided into a group of indolent lymphomas and a group of aggressive lymphomas [2,3,22]. Indolent lymphomas are characterized by slow growth and are generally considered incurable, although median survival is relatively long. On the other hand, aggressive lymphomas are characterized by rapid growth and can be treated curatively with relatively high survival rates [2,3]. If transformation from indolent to aggressive lymphoma (which eventually occurs in $40 \%$ of patients with an indolent lymphoma [2,3]) is clinically suspected, a biopsy should be performed for histologic confirmation. However, the lymphomatous site that contains the tumor cells with the highest malignancy grade can be missed by biopsy, as a result of which multiple or repeated biopsies may sometimes be needed. If DWI can predict which lymphomatous lesions contain the tumor cells with the highest malignancy grade, the number of biopsies and associated patient morbidity can be reduced. It can be hypothesized that differences in (sub)cellular structures between indolent and aggressive lymphomas may lead to different degrees of diffusivity. For example, grade I and II follicular lymphomas, which are the most common of the indolent lymphomas, consist of small- to intermediate-sized neoplastic cells that are closely packed [8], thus having a high cellular density. On the other hand, diffuse large B-cell lymphomas (which are the most common of the high-grade lymphomas) consist of larger neoplastic cells [8], which may correspond to a relatively lower cellular density. Since lesions with a higher cellularity are known to have a lower diffusivity than lesions with a lower cellularity [23-25], ADC measurements may also be of utility in predicting malignancy grade in patients with lymphoma.

The purposes of this study were to investigate whether ADC measurements allow discrimination of normal lymph nodes from lymphomatous lymph nodes, and indolent from aggressive lymphomas in patients with NHL.

\section{Materials and methods}

\section{Study participants}

This study was approved by the institutional review board of the University Medical Center Utrecht. All participants were enrolled after they had been properly informed and provided written informed consent. Eighteen healthy adult volunteers ( 9 men and 9 women; mean age, 22.9 years; age range, 19-37 years) were prospectively included, in order to determine ADCs of normal lymph nodes. Exclusion criteria for this volunteer study were previous surgery or malignancy, chronic or acute inflammation or infection, and current use of medicine. Furthermore, twenty-two consecutive patients with newly diagnosed NHL (21 men and 11 women; median age, 61.5 years; age range, 22-75 years; 16 indolent lymphomas, 16 aggressive lymphomas) were prospectively included, in order to determine ADCs of lymphomatous lymph nodes. All patients had undergone at least one excisional biopsy to histologically confirm the diagnosis of NHL. Biopsies had been examined by board-certified pathologists with expertise in lymphoma diagnosis, and NHLs had been classified as indolent or aggressive according to the recent WHO classification [22]. Characteristics of included patients are displayed in Table 1.

\section{MR imaging}

MR imaging was performed using a 1.5-T system (Achieva, Philips Healthcare, Best, The Netherlands) with a 4-element phased-array surface coil for signal reception in all body regions. In the volunteers, axial diffusion-weighted images of the head/neck and pelvis were acquired. In the patients, axial diffusion-weighted images of the head/neck, chest, abdomen, and pelvis were obtained. Note that DWI of the chest and abdomen was not acquired in the volunteers, because, in our experience, normal lymph nodes in these regions are usually not depicted at DWI. Applied sequence parameters for DWI were as follows: single-shot spin-echo echo-planar imaging, repetition time/echo time/inversion time of $8,612 / 78 / 180 \mathrm{~ms}$, slice thickness/gap of $4 / 0 \mathrm{~mm}$, number of slices of 60 , field of view of $450 \times 360 \mathrm{~mm}^{2}$, 
Table 1 Patient characteristics

\begin{tabular}{|c|c|c|c|c|}
\hline No. & Age (years) & Gender (M/F) & Lymphoma classification & Indolent/aggressive \\
\hline 1 & 29 & M & Diffuse large B-cell lymphoma & Aggressive \\
\hline 2 & 67 & M & Follicular lymphoma grade I-II & Indolent \\
\hline 3 & 60 & M & Diffuse large B-cell lymphoma & Aggressive \\
\hline 4 & 61 & $\mathrm{~F}$ & Diffuse large B-cell lymphoma & Aggressive \\
\hline 5 & 44 & $\mathrm{~F}$ & Diffuse large B-cell lymphoma & Aggressive \\
\hline 6 & 64 & $\mathrm{~F}$ & Diffuse large B-cell lymphoma & Aggressive \\
\hline 7 & 58 & M & Diffuse large B-cell lymphoma & Aggressive \\
\hline 8 & 62 & $\mathrm{~F}$ & Diffuse large B-cell lymphoma & Aggressive \\
\hline 9 & 56 & M & Small lymphocytic lymphoma & Indolent \\
\hline 10 & 66 & $\mathrm{~F}$ & Follicular lymphoma grade I-II & Indolent \\
\hline 11 & 62 & M & Diffuse large B-cell lymphoma & Aggressive \\
\hline 12 & 22 & M & Anaplastic large cell lymphoma & Aggressive \\
\hline 13 & 59 & M & Diffuse large B-cell lymphoma & Aggressive \\
\hline 14 & 74 & M & Diffuse large B-cell lymphoma & Aggressive \\
\hline 15 & 47 & M & Diffuse large B-cell lymphoma & Aggressive \\
\hline 16 & 58 & M & Nodal marginal zone lymphoma & Indolent \\
\hline 17 & 47 & M & Follicular lymphoma & Indolent \\
\hline 18 & 71 & $\mathrm{~F}$ & Lymphoplasmacytic lymphoma & Indolent \\
\hline 19 & 72 & $\mathrm{~F}$ & Nodal marginal zone lymphoma & Indolent \\
\hline 20 & 55 & M & Follicular lymphoma grade I-II & Indolent \\
\hline 21 & 60 & $\mathrm{~F}$ & Diffuse large B-cell lymphoma & Aggressive \\
\hline 22 & 64 & M & Follicular lymphoma grade I-II & Indolent \\
\hline 23 & 62 & $\mathrm{~F}$ & Extranodal marginal zone lymphoma & Indolent \\
\hline 24 & 68 & M & Low-grade B-cell lymphoma & Indolent \\
\hline 25 & 75 & M & Diffuse large B-cell lymphoma & Aggressive \\
\hline 26 & 54 & M & Follicular lymphoma grade I-II & Indolent \\
\hline 27 & 47 & M & Diffuse large B-cell lymphoma & Aggressive \\
\hline 28 & 71 & M & Follicular lymphoma grade I-II & Indolent \\
\hline 29 & 72 & $\mathrm{~F}$ & Follicular lymphoma grade I-II & Indolent \\
\hline 30 & 54 & M & Extranodal marginal zone lymphoma & Indolent \\
\hline 31 & 72 & $\mathrm{~F}$ & Angioimmunoblastic T-cell lymphoma & Aggressive \\
\hline 32 & 67 & M & Follicular lymphoma grade I-II & Indolent \\
\hline
\end{tabular}

acquisition matrix of $128 \times 81$, motion-probing gradients in three orthogonal axes, $b$-values of 0 and $1,000 \mathrm{~s} / \mathrm{mm}^{2}$, number of signal averages of 3 , half scan factor of 0.651 , parallel imaging (SENSitivity Encoding) factor of 2, echo train length of 43 , acquired voxel size of $3.52 \times 4.50 \times 4.00 \mathrm{~mm}^{3}$, reconstructed voxel size of $1.76 \times 1.76 \times 4.00 \mathrm{~mm}^{3}$, image acquisition under free breathing, and scan time of $4 \mathrm{~min}$ and $4 \mathrm{~s}$ for each of the four stations. Of note, at a high $b$-value of $1,000 \mathrm{~s} / \mathrm{mm}^{2}$, ADC measurements are relatively perfusion insensitive and theoretically more reflective of tissue cellularity and the integrity of cellular membranes [9]. Furthermore, a $b$-value of $1,000 \mathrm{~s} / \mathrm{mm}^{2}$ yields good background body signal suppression while highlighting lymphomatous lesions [4-6]. Axial trace ADC maps were created by signals obtained from images with the two $b$-values $\left(0\right.$ and $\left.1,000 \mathrm{~s} / \mathrm{mm}^{2}\right)$. In all patients, axial CT images of the neck, chest, abdomen, and pelvis, and coronal T1-weighted and short inversion time inversion recovery (STIR) whole-body MR images were acquired in addition to axial DWI.

Image analysis

All MR images were transferred to a workstation (ViewForum; Philips Healthcare, Best, The Netherlands). One observer R.A.J.N., with fourteen years of experience in MR imaging), reviewed the images of the volunteers, and another observer T.C.K., with more than two years of experience in DWI), reviewed the images of the patients. Both observers knew that they were evaluating scans from 
either healthy subjects or patients with NHL. However, each observer was blinded to the results of the other observer. Furthermore, the second observer was blinded to the lymphoma type of the patients, other clinical and imaging information, and follow-up findings. In the volunteers, the largest normal lymph node was identified, and a region of interest (ROI) was placed in this lymph node on the image that was obtained at a $b$-value of $1,000 \mathrm{~s} / \mathrm{mm}^{2}$. This ROI was placed on the slice containing the largest portion of the lymph node, in order to minimize partial volume averaging effects. Each ROI was variable so that it included as much of the nodal parenchyma as possible, but edges of the lymph node were not included. Accurate localization of the ROI was checked on the image obtained at a $b$-value of $0 \mathrm{~s} / \mathrm{mm}^{2}$. The ROI was then copied and pasted onto the ADC map, and the mean ADC of the lymph node was automatically calculated.
In the patients, lymph nodes were considered lymphomatous in case their short-axis diameter clearly exceeded $10 \mathrm{~mm}$ on CT, T1-weighted, and STIR whole-body MR images, as is common in the evaluation of malignant lymphoma [26]. Furthermore, the lymph nodes with a short-axis diameter larger than $10 \mathrm{~mm}$ also had to be positive at pretherapy ${ }^{18} \mathrm{~F}$-fluoro-2deoxy-D-glucose positron emission tomography (FDG-PET) or decrease in size on follow-up CT studies after therapy (minimum follow-up time of 6 months) if pretherapy FDGPET was not performed. Decrease in size on follow-up CT studies was defined as an at least $50 \%$ decrease in the sum of the product of the perpendicular diameters of the involved lymph node from baseline (Fig. 1), which is partly in line with the recently revised response criteria for lymphoma [27]. In each patient, the largest lymphomatous lymph node was identified on the CT, T1-weighted, and STIR whole-body MR



Fig. 1 Baseline (pretherapy) CT (a) and 6-month posttherapy CT (b) in a 54-year-old man with follicular lymphoma. Baseline CT (a) shows a pathologically enlarged right axillary lymph node $(3.5 \mathrm{~cm} \times 3.5 \mathrm{~cm})$ (arrow) that was selected for ADC analysis. At 6-month posttherapy CT (b), only small axillary lymph nodes with perpendicular diameters less than $1.0 \mathrm{~cm}$ are visible (arrow), which confirms that the right axillary lymph node at baseline $\mathrm{CT}$ was indeed lymphomatous

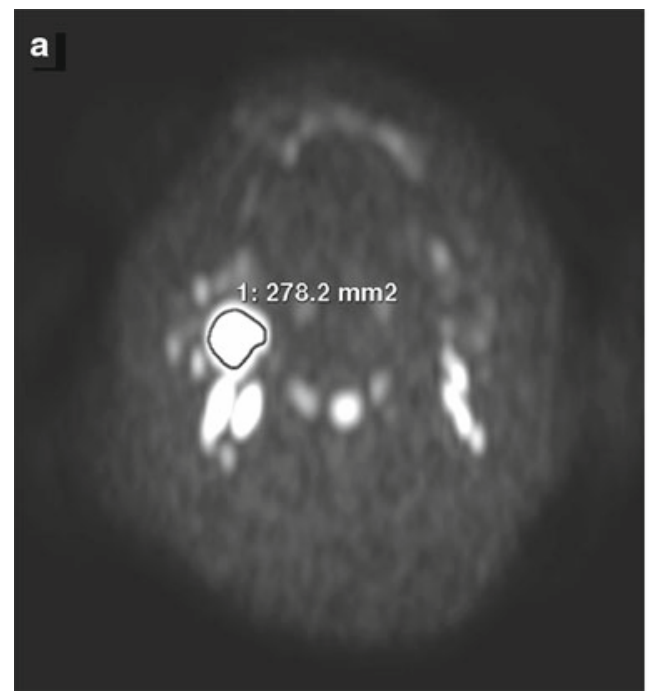

Fig. 2 Example of an ADC measurement of a lymphomatous cervical lymph node in a 60-year-old woman with diffuse large B-cell lymphoma. A freehand ROI was placed in the lymphomatous cervical lymph node, on the image obtained at a $b$-value of $1,000 \mathrm{~s} / \mathrm{mm}^{2}$ (a). The ROI

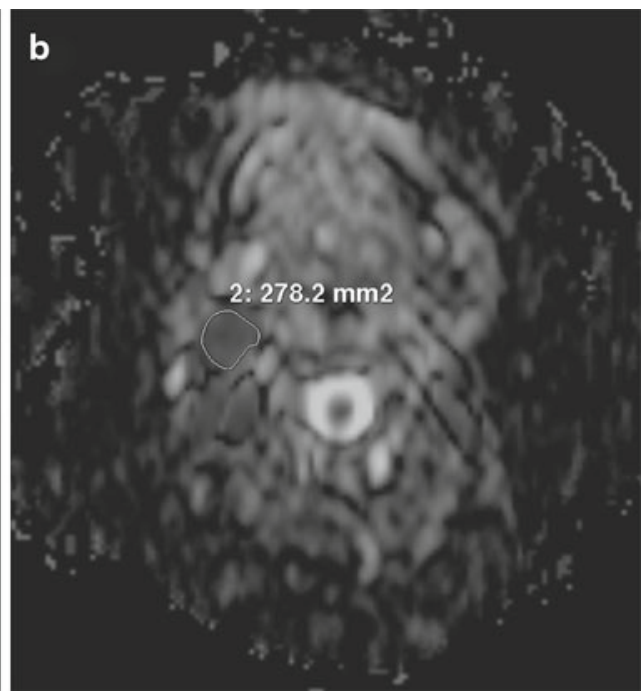

was then copied and pasted onto the ADC map (b), and the ADC of the lymphomatous lesion (in this case $0.74 \times 10^{-3} \mathrm{~mm}^{2} / \mathrm{s}$ ) was automatically calculated 


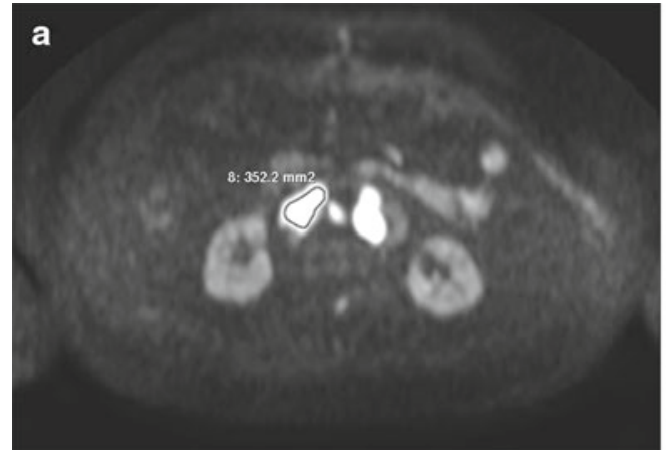

Fig. 3 Example of an ADC measurement of a lymphomatous paraaortic lymph node in a 72-year-old woman with nodal marginal zone lymphoma. A freehand ROI was placed in the lymphomatous para-aortic lymph node, on the image obtained at a $b$-value of $1,000 \mathrm{~s} / \mathrm{mm}^{2}$ (a).

images, and its ADC was measured as described previously. When lymph nodes showed heterogeneous signal intensity on native $\left(b=1,000 \mathrm{~s} / \mathrm{mm}^{2}\right)$ diffusion-weighted images, only the solid-appearing portions (i.e. high signal intensity) were included in the ROI, while obvious necrotic components (i.e. low signal intensity) were excluded from the ROI. Of note, only the largest lymph node in each healthy volunteer and the largest lymphomatous lymph node in each patient were analyzed in order to avoid selection and clustering bias [28]. Selecting the largest lymph node in both populations also reduced inaccuracies in ADC measurements due to partial volume effects. Representative examples of ADC measurements are shown in Figs. 2 and 3.

\section{Statistical analysis}

Kolmogorov-Smirnov tests were used to check whether ADCs of the different groups were normally distributed. ADCs of normal lymph nodes were compared to those of lymphomatous lymph nodes, and ADCs of indolent lymphomas were compared to those of aggressive lymphomas, using unpaired two-tailed $t$ tests. In case the unpaired $t$ tests revealed a significant difference in ADCs between two of the aforementioned groups, additional receiver operating characteristic (ROC) analysis was performed to determine the area under the ROC curve and the optimal cutoff ADC value with corresponding sensitivity and specificity. $P$ values less than 0.05 were considered to indicate a statistically significant difference. Statistical analyses were executed using MedCalc version 10.4.5.0 software (MedCalc, Mariakerke, Belgium).

\section{Results}

All diffusion-weighted images were of diagnostic quality, without any disturbing (susceptibility or motion) artifacts

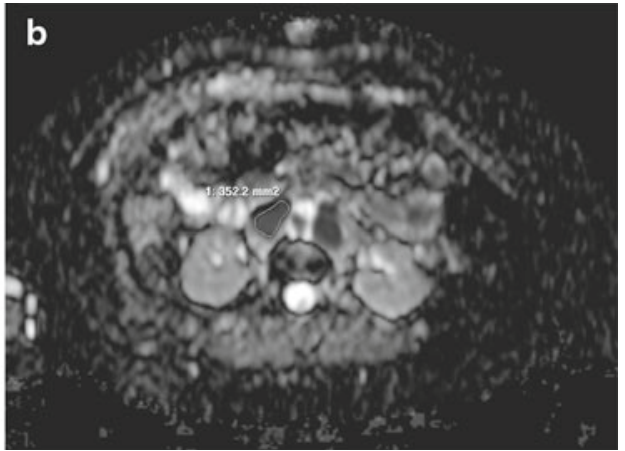

The ROI was then copied and pasted onto the ADC map (b), and the $\mathrm{ADC}$ of the lymphomatous lesion (in this case $0.51 \times 10^{-3} \mathrm{~mm}^{2} / \mathrm{s}$ ) was automatically calculated

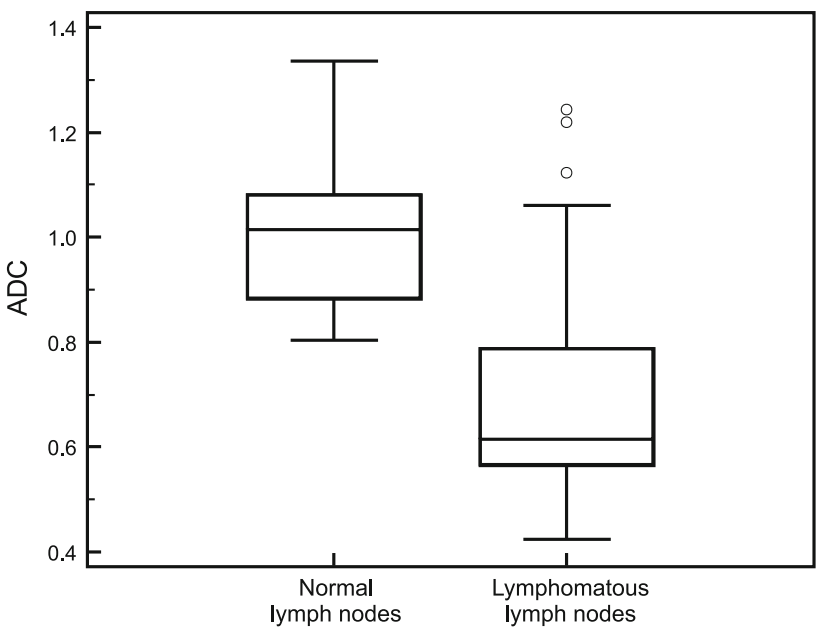

Fig. 4 Box-and-whisker plots show median (middle line of box), quartiles (top and bottom lines of box), upper extreme value (upper whisker), lower extreme value (lower whisker), and outliers (circles) for ADCs (in $10^{-3} \mathrm{~mm}^{2} / \mathrm{s}$ ) according to nodal status (normal vs. lymphomatous). ADCs of lymphomatous lymph nodes (mean $\pm \mathrm{SD}, 0.70 \pm 0.22$ ) were significantly lower $(P \leq 0.0001)$ than those of normal lymph nodes $($ mean $\pm \mathrm{SD}, 1.00 \pm 0.15)$

(Figs. 2, 3). ROIs for ADC measurements of normal lymph nodes in the volunteers were placed in left cervical $(n=6)$, right cervical $(n=6)$, right axillary $(n=1)$, left inguinal $(n=1)$, and right inguinal $(n=4)$ lymph nodes. Mean size of ROIs in the volunteers was $56 \mathrm{~mm}^{2}$ (standard deviation, $19 \mathrm{~mm}^{2}$; range, 28-87 $\mathrm{mm}^{2}$ ). ROIs for ADC measurements of lymphomatous lymph nodes in the patients were placed in left cervical $(n=4)$, right cervical $(n=2)$, left axillary $(n=4)$, right axillary $(n=6)$, para-aortic $(n=8)$, mesenteric $(n=2)$, left perirenal $(n=1)$, left inguinal $(n=2)$, and right inguinal $(n=3)$ lymph nodes. Lymphomatous involvement of these lymph nodes was confirmed by pretherapy FDG-PET in 18 patients and by follow-up CT studies in 14 patients. Mean size of ROIs in the patients was $908 \mathrm{~mm}^{2}$ (standard 
deviation, $1,144 \mathrm{~mm}^{2}$; range, $120-4,134 \mathrm{~mm}^{2}$ ). Kolmogorov-Smirnov tests confirmed that the ADCs of the different groups were normally distributed, justifying comparisons by means of unpaired $t$ tests.

ADCs (in $10^{-3} \mathrm{~mm}^{2} / \mathrm{s}$ ) of lymphomatous lymph nodes (mean $\pm \mathrm{SD}, 0.70 \pm 0.22)$ were significantly lower $(P<$ 0.0001 ) than those of normal lymph nodes (mean $\pm \mathrm{SD}$, $1.00 \pm 0.15$ ). Box-and-whisker plots with ADCs according to nodal status (normal vs. lymphomatous) are shown in Fig. 4. Area under the ROC curve was 0.865 (95\% CI: 0.738-0.945). The ROC curve is displayed in Fig. 5. Sensitivity was $78.1 \%$ (95\% CI: $60.0-90.7 \%$ ) and specificity was

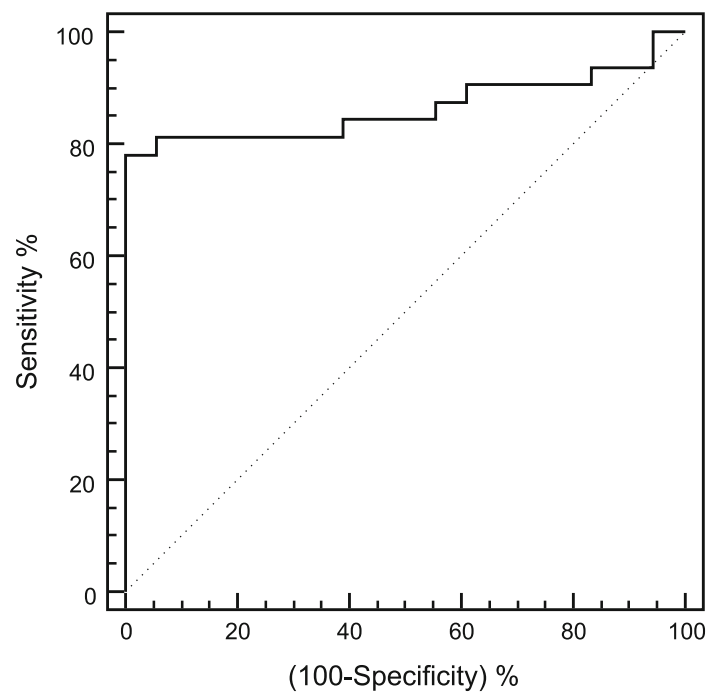

Fig. 5 ROC curve for ADC measurements for the determination of nodal status (normal vs. lymphomatous). Area under the ROC curve was 0.865 (95\% CI $0.738-0.945)$

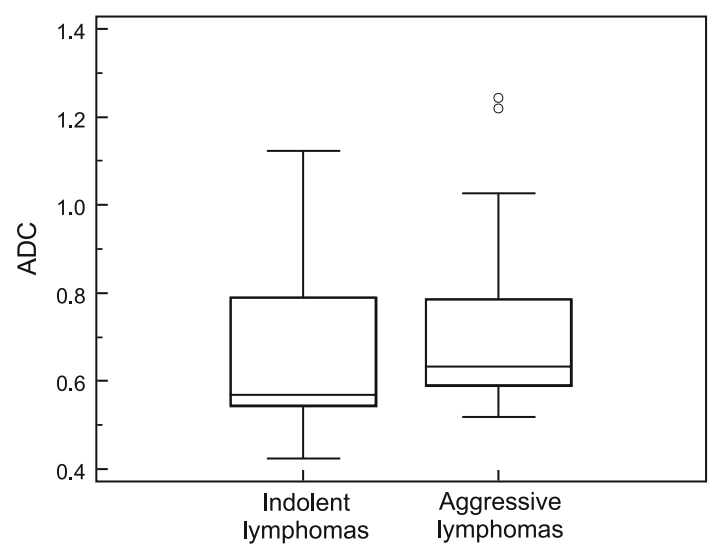

Fig. 6 Box-and-whisker plots show median (middle line of box), quartiles (top and bottom lines of box), upper extreme value (upper whisker), lower extreme value (lower whisker), and outliers (circles) for ADCs (in $10^{-3} \mathrm{~mm}^{2} / \mathrm{s}$ ) according to lymphoma type (indolent vs. aggressive). ADCs of indolent lymphomas (mean $\pm \mathrm{SD}, 0.67 \pm 0.21$ ) were not significantly different $(P=0.2997)$ from those of aggressive lymphomas $($ mean $\pm \mathrm{SD}, 0.74 \pm 0.23$ )
$100 \%$ (95\% CI: $81.5-100 \%)$ when using an optimal cutoff ADC value of 0.80 .

ADCs of indolent lymphomas (mean $\pm \mathrm{SD}, 0.67 \pm 0.21$ ) were not significantly different $(P=0.3691)$ from those of aggressive lymphomas (mean $\pm \mathrm{SD}, 0.74 \pm 0.23$ ). Box-andwhisker plots with ADCs according to lymphoma type (indolent vs. aggressive) are shown in Fig. 6.

\section{Discussion}

Accurate assessment of spread of nodal disease in patients with NHL is important for determining prognosis and treatment planning $[2,3]$. The relatively recent development of whole-body DWI $[29,30]$ made it a feasible technique for staging NHL [4-6]. DWI not only allows visualizing anatomic abnormalities, but it also provides functional information in that it allows quantification of the random motion of water molecules (i.e. diffusion) by means of ADC measurements [31]. The ADC may provide a reflection of anatomic and functional cellular characteristics. For example, the ADC has shown to be inversely correlated to the tissue cellularity and the integrity of cell membranes [23-25]. As such, it may aid in the characterization of lesions [9], including the assessment of lymph nodes in patients with NHL. Previous studies in patients presenting with cervical lymphadenopathy have reported ADCs (in $10^{-3} \mathrm{~mm}^{2} / \mathrm{s}$ ) of lymphomatous lymph nodes of $0.22 \pm 0.056$ [10], $0.449 \pm 0.096$ (without nodal necrosis) [11], $0.601 \pm 0.427$ [12], $0.64 \pm 0.09$ [15], $0.664 \pm 0.071$ [14], $0.97 \pm 0.27$ [13], and $1.091 \pm 0.405$ (with nodal necrosis) [11]. Note that reported ADCs of lymphomatous lymph nodes vary widely, which can be explained by different ways of ADC measurements (e.g. measurement of the entire lymph node will result in a higher ADC than in a measurement in which necrotic regions are excluded) and the use of different $b$-values. Nevertheless, all previous studies [10-15] reported that ADCs of lymphomatous lymph nodes are generally lower than those of metastatic lymph nodes and benign lymphadenopathy. However, the utility of ADC measurements in the assessment of lymph nodes in the staging workup of patients with NHL was still unknown, because previous studies only investigated whether ADC measurements allow histologic differentiation of pathologic lymph nodes rather than assessing whether they can discriminate normal from lymphomatous lymph nodes. Interestingly, ADC measurements may also be used as a noninvasive predictor of malignancy grade. Several studies have shown that ADC measurements may aid in grading brain tumors [23,24,3236 , with high-grade brain tumors having a lower ADC than low-grade brain tumors, probably due to higher cellularity of the former. However, the value of ADC measurements in grading NHLs was still unknown. 
In the present study, ADCs (in $10^{-3} \mathrm{~mm}^{2} / \mathrm{s}$ ) of lymphomatous lymph nodes in patients with NHL $(0.70 \pm 0.22)$ were significantly lower than those of normal lymph nodes in healthy volunteers $(1.00 \pm 0.15)$. Furthermore, ROC analysis showed that a sensitivity of $78.1 \%$ (95\% CI 60.0-90.7\%) and a specificity of $100 \%$ (95\% CI $81.5-100 \%)$ can be achieved when using an optimal cutoff ADC value of 0.80 . This may suggest that a lymph node with an ADC lower than 0.78 in a patient with NHL is probably lymphomatous. This finding can be explained by the fact that most lymphoma types mostly consist of densely packed cellular tissue with very little extracellular space [8], which considerably impedes the diffusivity of water molecules. On the other hand, our results indicate that ADC measurements in DWI do not allow discrimination of indolent from aggressive lymphomas, given the nonsignificant difference in ADCs between both groups. A possible explanation for this finding may be that cellular density of indolent lymphomas is not too different from that of aggressive lymphomas.

This study had several limitations. First, because of the insensitivity of size criteria to diagnose lymphomatous involvement of normal-sized lymph nodes [7] and the practical and ethical impossibility to obtain additional biopsies in the patients with NHL, only enlarged lymphomatous lymph nodes could be evaluated. In addition, a group of healthy volunteers had to be included to determine the ADC of normal lymph nodes. Although the volunteers were considerably younger than the patients, there is no reason to assume why (ADCs of) lymph nodes in a young population would differ from those in an older population [8]. Furthermore, the same imaging protocol and the same ADC measurement method were applied in both the healthy volunteers and the patients. Second, the site of ADC measurement did not correspond to the site of the initial biopsy in any of the patients. This is because imaging for staging takes place after the diagnosis of NHL has been established by means of excisional biopsy. Obtaining additional biopsies of the lymphomatous lymph nodes that were used for ADC analysis would be most desirable, but was simply impossible due to aforementioned reasons. Nevertheless, accepted diagnostic criteria for nodal involvement in NHL [26] were used and pretherapy FDG-PET or follow-up CT studies were reviewed to confirm that the lymph nodes of the patients that were analyzed were indeed lymphomatous. Furthermore, although we cannot exclude the coexistence of aggressive disease in patients with newly diagnosed indolent lymphoma, this probability is very low, because high-grade transformation typically occurs only months to years after initial diagnosis [37-39]. In addition, none of the patients with indolent lymphoma had clinical features (e.g. considerably elevated lactate dehydrogenase or rapid lymphoma growth) that would suggest high-grade transformation. Third, lymph nodes in the healthy volunteers that were selected for ADC measurements did not match to those of the patients with respect to location and size, but this limitation was inherent to the chosen study design. Fourth, the degree of confidence that can be ascribed to measuring ADCs of normal-sized lymph nodes in healthy volunteers is uncertain. Fifth, only two $b$-values $\left(0\right.$ and $\left.1,000 \mathrm{~s} / \mathrm{mm}^{2}\right)$ were used for ADC calculation. It may have been desirable to acquire more $b$-values in order to obtain more accurate ADCs [9]. However, this would considerably prolong scan time. It should also be mentioned that the use of different MR parameters (in particular the number of $b$-values) and different methods of ROI analysis (e.g. inclusion of necrotic areas) may have resulted in different ADCs, which limits the general applicability of the ADC threshold that was obtained in the present study. Despite these study limitations, the present results indicate that ADC measurements may be used as an additional tool in the assessment of lymph nodes (e.g. in case of borderline lymph node enlargement at anatomic imaging) in the staging workup of patients with NHL.

\section{Conclusion}

In conclusion, our results suggest that ADC measurements show promise as a highly specific tool for the discrimination of normal lymph nodes from lymphomatous lymph nodes in patients with NHL. However, ADC measurements appear to be of no utility in differentiating indolent from aggressive lymphomas.

Acknowledgments This study was supported by ZonMw programme for Health Care Efficiency Research (grant number 80-82310-9808012).

Open Access This article is distributed under the terms of the Creative Commons Attribution Noncommercial License which permits any noncommercial use, distribution, and reproduction in any medium, provided the original author(s) and source are credited.

\section{References}

1. Jemal A, Siegel R, Ward E, Hao Y, Xu J, Thun MJ (2009) Cancer statistics, 2009. CA Cancer J Clin 59:225-249

2. Ansell SM, Armitage J (2005) Non-Hodgkin lymphoma: diagnosis and treatment. Mayo Clin Proc 80:1087-1097

3. Evans LS, Hancock BW (2003) Non-Hodgkin lymphoma. Lancet 362:139-146

4. Kwee TC, van Ufford HM, Beek FJ, Takahara T, Uiterwaal CS, Bierings MB, Ludwig I, Fijnheer R, Nievelstein RA (2009) Wholebody MRI, including diffusion-weighted imaging, for the initial staging of malignant lymphoma: comparison to computed tomography. Invest Radiol 44:683-690

5. Li S, Xue HD, Li J, Sun F, Jiang B, Liu D, Sun HY, Jin ZY (2008) Application of whole body diffusion weighted MR imaging for diagnosis and staging of malignant lymphoma. Chin Med Sci J 23:138-144

6. Lin C, Luciani A, Itti E, El-Gnaoui T, Vignaud A, Beaussart P, Lin SJ, Belhadj K, Brugières P, Evangelista E, Haioun C, Meignan M, Rahmouni A (2010) Whole-body diffusion-weighted magnetic 
resonance imaging with apparent diffusion coefficient mapping for staging patients with diffuse large B-cell lymphoma. Eur Radiol 20:2027-2038

7. Torabi M, Aquino SL, Harisinghani MG (2004) Current concepts in lymph node imaging. J Nucl Med 45:1509-1518

8. Ioachim HL, Medeiros LJ (2008) Ioachim's lymph node pathology. Lippincott Williams and Wilkins, Philadelphia

9. Padhani AR, Liu G, Koh DM, Chenevert TL, Thoeny HC, Takahara T, Dzik-Jurasz A, Ross BD, Van Cauteren M, Collins D, Hammoud DA, Rustin GJ, Taouli B, Choyke PL (2009) Diffusion-weighted magnetic resonance imaging as a cancer biomarker: consensus and recommendations. Neoplasia 11:102-125

10. Sumi M, Van Cauteren M, Nakamura T (2006) MR microimaging of benign and malignant nodes in the neck. AJR Am J Roentgenol 186:749-757

11. Sumi M, Nakamura T (2009) Diagnostic importance of focal defects in the apparent diffusion coefficient-based differentiation between lymphoma and squamous cell carcinoma nodes in the neck. Eur Radiol 19:975-981

12. Sumi M, Sakihama N, Sumi T, Morikawa M, Uetani M, Kabasawa H, Shigeno K, Hayashi K, Takahashi H, Nakamura T (2003) Discrimination of metastatic cervical lymph nodes with diffusionweighted MR imaging in patients with head and neck cancer. AJNR Am J Neuroradiol 24:1627-1634

13. Abdel Razek AA, Soliman NY, Elkhamary S, Alsharaway MK, Tawfik A (2006) Role of diffusion-weighted MR imaging in cervical lymphadenopathy. Eur Radiol 16:1468-1477

14. King AD, Ahuja AT, Yeung DK, Fong DK, Lee YY, Lei KI, Tse GM (2007) Malignant cervical lymphadenopathy: diagnostic accuracy of diffusion-weighted MR imaging. Radiology 245:806881

15. Holzapfel K, Duetsch S, Fauser C, Eiber M, Rummeny EJ, Gaa J (2009) Value of diffusion-weighted MR imaging in the differentiation between benign and malignant cervical lymph nodes. Eur J Radiol 72:381-387

16. Kim JK, Kim KA, Park BW, Kim N, Cho KS (2008) Feasibility of diffusion-weighted imaging in the differentiation of metastatic from nonmetastatic lymph nodes: early experience. J Magn Reson Imaging 28:714-719

17. Vandecaveye V, De Keyzer F, Vander Poorten V, Dirix P, Verbeken E, Nuyts S, Hermans R (2009) Head and neck squamous cell carcinoma: value of diffusion-weighted MR imaging for nodal staging. Radiology 251:134-146

18. Sakurada A, Takahara T, Kwee TC, Yamashita T, Nasu S, Horie T, Van Cauteren M, Imai Y (2009) Diagnostic performance of diffusion-weighted magnetic resonance imaging in esophageal cancer. Eur Radiol 19:1461-1469

19. Park SO, Kim JK, Kim KA, Park BW, Kim N, Cho G, Choi HJ, Cho KS (2009) Relative apparent diffusion coefficient: determination of reference site and validation of benefit for detecting metastatic lymph nodes in uterine cervical cancer. J Magn Reson Imaging 29:383-390

20. Yasui O, Sato M, Kamada A (2009) Diffusion-weighted imaging in the detection of lymph node metastasis in colorectal cancer. Tohoku J Exp Med 218:177-183

21. de Bondt RB, Hoeberigs MC, Nelemans PJ, Deserno WM, PeutzKootstra C, Kremer B, Beets-Tan RG (2009) Diagnostic accuracy and additional value of diffusion-weighted imaging for discrimination of malignant cervical lymph nodes in head and neck squamous cell carcinoma. Neuroradiology 51:183-192

22. Swerdlow SH, Campo E, Harris NL, Pileri SA, Stein H, Thiele J, Vardiman JW (2008) WHO classification of tumours of haematopoietic and lymphoid tissues, 4th edn. International Agency for Research on Cancer, Lyon

23. Hayashida Y, Hirai T, Morishita S, Kitajima M, Murakami R, Korogi Y, Makino K, Nakamura H, Ikushima I, Yamura M, Kochi
M, Kuratsu JI, Yamashita Y (2006) Diffusion-weighted imaging of metastatic brain tumors: comparison with histologic type and tumor cellularity. AJNR Am J Neuroradiol 27:1419-1425

24. Sugahara T, Korogi Y, Kochi M, Ikushima I, Shigematu Y, Hirai T, Okuda T, Liang L, Ge Y, Komohara Y, Ushio Y, Takahashi M (1999) Usefulness of diffusion-weighted MRI with echo-planar technique in the evaluation of cellularity in gliomas. J Magn Reson Imaging 9:53-60

25. Schnapauff D, Zeile M, Niederhagen MB, Fleige B, Tunn PU, Hamm B, Dudeck O (2009) Diffusion-weighted echo-planar magnetic resonance imaging for the assessment of tumor cellularity in patients with soft-tissue sarcomas. J Magn Reson Imaging 29:1355-1359

26. Tatsumi M, Cohade C, Nakamoto Y, Fishman EK, Wahl RL (2005) Direct comparison of FDG PET and CT findings in patients with lymphoma: initial experience. Radiology 237:10381045

27. Cheson BD, Pfistner B, Juweid ME, International Harmonization Project on Lymphoma et al (2007) Revised response criteria for malignant lymphoma. J Clin Oncol 25:579-586

28. Sica GT (2006) Bias in research studies. Radiology 238:780-789

29. Takahara T, Imai Y, Yamashita T, Yasuda S, Nasu S, Van Cauteren M (2004) Diffusion weighted whole body imaging with background body signal suppression (DWIBS): technical improvement using free breathing, STIR and high resolution 3D display. Radiat Med 22:275-282

30. Kwee TC, Takahara T, Ochiai R, Nievelstein RA, Luijten PR (2008) Diffusion-weighted whole-body imaging with background body signal suppression (DWIBS): features and potential applications in oncology. Eur Radiol 18:1937-1952

31. Le Bihan D, Breton E, Lallemand D, Aubin ML, Vignaud J, Laval-Jeantet M (1988) Separation of diffusion and perfusion in intravoxel incoherent motion MR imaging. Radiology 168:497-505

32. Murakami R, Hirai T, Sugahara T, Fukuoka H, Toya R, Nishimura S, Kitajima M, Okuda T, Nakamura H, Oya N, Kuratsu J, Yamashita Y (2009) Grading astrocytic tumors by using apparent diffusion coefficient parameters: superiority of a one- versus two-parameter pilot method. Radiology 251:838-845

33. Arvinda HR, Kesavadas C, Sarma PS, Thomas B, Radhakrishnan VV, Gupta AK, Kapilamoorthy TR, Nair S (2009) Glioma grading: sensitivity, specificity, positive and negative predictive values of diffusion and perfusion imaging. J Neurooncol 94:87-96

34. Lee EJ, Lee SK, Agid R, Bae JM, Keller A, Terbrugge K (2008) Preoperative grading of presumptive low-grade astrocytomas on MR imaging: diagnostic value of minimum apparent diffusion coefficient. AJNR Am J Neuroradiol 29:1872-1877

35. Higano S, Yun X, Kumabe T, Watanabe M, Mugikura S, Umetsu A, Sato A, Yamada T, Takahashi S (2006) Malignant astrocytic tumors: clinical importance of apparent diffusion coefficient in prediction of grade and prognosis. Radiology 241:839-846

36. Bulakbasi N, Guvenc I, Onguru O, Erdogan E, Tayfun C, Ucoz $\mathrm{T}$ (2004) The added value of the apparent diffusion coefficient calculation to magnetic resonance imaging in the differentiation and grading of malignant brain tumors. J Comput Assist Tomogr 28:735-746

37. Bastion Y, Sebban C, Berger F, Felman P, Salles G, Dumontet C, Bryon PA, Coiffier B (1997) Incidence, predictive factors, and outcome of lymphoma transformation in follicular lymphoma patients. J Clin Oncol 15:1587-1594

38. O'Brien ME, Easterbrook P, Powell J, Blackledge GR, Jones L, MacLennan IC, Leonard RC (1991) The natural history of low grade non-Hodgkin's lymphoma and the impact of a no initial treatment policy on survival. Q J Med 80:651-660

39. Horning SJ, Rosenberg SA (1984) The natural history of initially untreated low-grade non-Hodgkin's lymphomas. N Engl J Med 311:1471-1475 